\title{
High-Velocity Impact Behaviour of Prestressed Composite Plates under Bird Strike Loading
}

\author{
Sebastian Heimbs and Tim Bergmann \\ Department of Structures Engineering, Production and Aeromechanics, EADS Innovation Works, Willy-Messerschmitt-Straße, \\ 81663 Munich, Germany \\ Correspondence should be addressed to Sebastian Heimbs, sebastian.heimbs@eads.net
}

Received 11 October 2011; Revised 12 January 2012; Accepted 17 January 2012

Academic Editor: Mark Price

Copyright (๑) 2012 S. Heimbs and T. Bergmann. This is an open access article distributed under the Creative Commons Attribution License, which permits unrestricted use, distribution, and reproduction in any medium, provided the original work is properly cited.

\begin{abstract}
An experimental and numerical analysis of the response of laminated composite plates under high-velocity impact loads of soft body gelatine projectiles (artificial birds) is presented. The plates are exposed to tensile and compressive preloads before impact in order to cover realistic loading conditions of representative aeronautic structures under foreign object impact. The modelling methodology for the composite material, delamination interfaces, impact projectile, and preload using the commercial finite element code Abaqus are presented in detail. Finally, the influence of prestress and of different delamination modelling approaches on the impact response is discussed and a comparison to experimental test data is given. Tensile and compressive preloading was found to have an influence on the damage pattern. Although this general behaviour could be predicted well by the simulations, further numerical challenges for improved bird strike simulation accuracy are highlighted.
\end{abstract}

\section{Introduction}

The application of carbon fibre-reinforced plastic (CFRP) materials in aircraft structures is ever-expanding. Besides established utilisation in control surfaces or wing structures, the latest generation of commercial airliners also feature a fuselage made of carbon fibre composite material. Besides their well-known advantages in terms of weight-specific mechanical properties and fatigue tolerance, such structures are vulnerable against transversal impact loads, which can lead to undetectable internal damage and cracks that can reduce the strength and grow under load. Typical examples of such impact load cases with frequent occurrence are bird strike loads on composite wing leading edges or hard body impact loads from stones or runway debris being thrown against lower fuselage panels by the aircraft tires.

Most studies that have been performed so far to investigate the impact performance of composite laminates are based on unloaded structures. However, this simplification may be far off reality as the structure in flight may typically be under a state of prestress before impact. For example, the lower fuselage panels are typically exposed to compressive loads during takeoff, when stone impact is likely to occur. There is a strong interest in investigating the influence of preloads on the impact response of aeronautic structures.

Most published studies on this topic are based on lowvelocity impact loads, which can experimentally be achieved on a drop tower test rig with a falling mass impacting the preloaded sample [1-3] or using an instrumented pendulum test rig [4-6]. During such tests, the investigation of tensile preloads is comparably easy to perform and has been conducted in [7-16]. Compressive preloads, in contrast, introduce the complexity of plate buckling, which was analysed by Heimbs et al. [17], Zhang et al. [18], and Morlo and Kunz [19]. Choi [20], Sun and Chen [21], Sun and Chattopadhyay [22] and Khalili et al. [23] present analytical studies of the low-velocity impact response of composite plates under compressive and tensile preload.

The high-velocity impact response of preloaded laminated composite structures was investigated in only very few studies. For this purpose, a gas cannon is typically used, which accelerates the projectile to velocities of approximately $50-300 \mathrm{~m} / \mathrm{s}$. In the study of Herszberg et al. [24] a $13 \mathrm{~mm}$ 


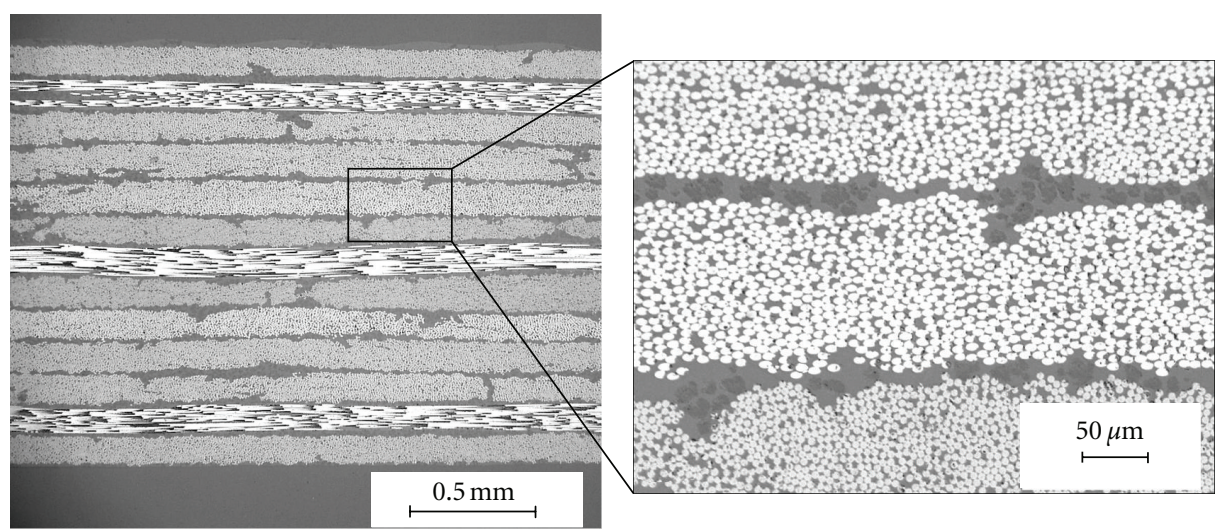

FIgURE 1: Micrograph of T800S/M21 composite laminate plate.

steel sphere was fired with velocities from $20 \mathrm{~m} / \mathrm{s}$ to $70 \mathrm{~m} / \mathrm{s}$ against a $2 \mathrm{~mm}$ carbon fibre/epoxy plate with tensile preload leading to a change in damage pattern for higher preloads. Schueler et al. [25] present an experimental and numerical study of the high-velocity impact response of 17-ply CFRP plates under tensile preload using a $21 \mathrm{~g}$ glass sphere projectile and an impact velocity of $64 \mathrm{~m} / \mathrm{s}$, obtaining less delamination compared to the unloaded case. Their numerical model in Abaqus was based on stacked continuum shell elements with cohesive element interfaces in between. General trends found during the experiments could also be drawn from the simulation results. Vaidya and Shafiq [26] performed ballistic impact tests on $4.5 \mathrm{~mm}$ thick woven E-glass/vinylester plates with compressive preload and velocities roughly in the range of $100-300 \mathrm{~m} / \mathrm{s}$ and report a detrimental effect on the residual strength of the composite plate. Garcia-Castillo et al. [27, 28] performed ballistic impact tests on $3.19 \mathrm{~mm}$ thick woven E-glass/polyester plates with biaxial tensile preload using a $7.5 \mathrm{~mm}$ steel sphere and velocities from $140 \mathrm{~m} / \mathrm{s}$ to $525 \mathrm{~m} / \mathrm{s}$. They report an increase of the ballistic limit for the preloaded plates, correlating to their analytical and numerical Abaqus model.

An investigation on the effect of prestress on the highvelocity impact behaviour of laminated composite structures under soft body impacts has not been performed yet. This effect can be of great importance for bird strike analyses and bird-proof design of composite aircraft structures, though. There is a big difference between the spread contact area of soft body impact loads resulting from bird or hail strike compared to hard body impact loads, which are resulting from bird strike compared much more localised. For simplification and generalisation of this study, the soft body impact on a flat composite plate was analysed. The intention was to assess the influence of preload on the damage behaviour both experimentally and numerically, using the commercial finite element (FE) code Abaqus V6.10.

\section{Experiments}

This study was based on an experimental test campaign in order to obtain a reliable data basis for model validations. The central part of this test campaign was high-velocity impact tests with soft body projectiles on simple flat composite plates under compressive or tensile preload.

The carbon fibre/epoxy laminated plates were made from 13 plies of Hexcel T800S/M21 prepreg with a stacking sequence of $[+45 / 90 /-45 /+45 /-45 / 0 / 90 / 0 /-45 /+45 /-45 /$ $90 /+45]$ and a nominal thickness of $1.625 \mathrm{~mm}$. The micrograph in Figure 1 shows a cross-section of the laminate with the dark areas between the plies not being cracks or manufacturing imperfections but conglomerations of thermoplastic interleaf particles of the resin system for enhanced impact damage tolerance. The plates were cured in an autoclave at $180^{\circ} \mathrm{C}$ and 7 bar pressure for 120 minutes. Standard coupon tests of this material were performed as part of the test campaign in order to obtain the elastic, strength, and damage properties that are necessary for the numerical material modelling.

The final specimens for the impact tests had a size of $550 \mathrm{~mm} \times 200 \mathrm{~mm}$ with bonded metallic end tabs of $125 \mathrm{~mm}$ length for the fixation in the preloading device, reducing the free specimen length to $300 \mathrm{~mm} \times 200 \mathrm{~mm}$ (Figure 2). A total of six strain gauges were used for the plates with compressive preload in order to accurately determine the prestrain and buckling pattern. Three strain gauges were used for the plates with tensile preload or without preload.

The bird impact tests were performed at the DLR Stuttgart gas cannon test facility using a specially designed test rig that allows for uniaxial tensile or compressive preloading. The longitudinal ends with the metallic end tabs were clamped to the machine, and the lateral ends were simply supported from both sides. A small gelatine projectile of $32 \mathrm{~g}$ weight and a cylindrical geometry with one hemispherical end cap was used as a typical small artificial bird impactor (Figure 3(a)). Impact velocities of $93-171 \mathrm{~m} / \mathrm{s}$ or kinetic energies of 135-443 J were tested. Three different preloading conditions were applied:

(i) tensile prestrain of $0.25 \%$, which is a typical value for the limit load of this structure,

(ii) unloaded,

(iii) compressive preload of $11 \mathrm{kN}$, which is 2.15 times higher than the experimentally determined buckling load and represents the ultimate load for this structure. 


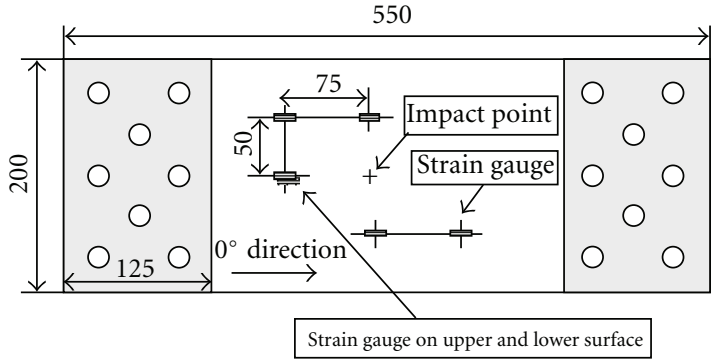

(a)

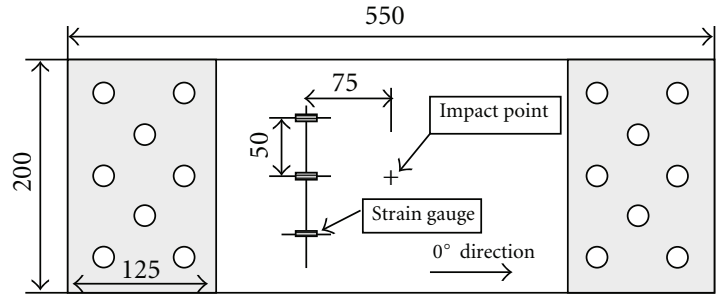

(b)

FIGURE 2: Impact specimen dimensions (in $\mathrm{mm}$ ) and position of strain gauges for (a) compressive preload and (b) tensile preload.

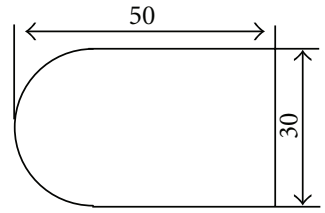

(a)

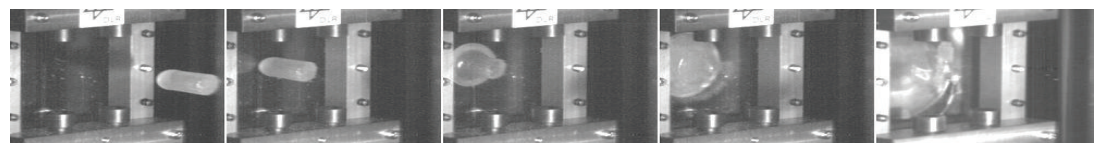

(b)

FIGURE 3: (a) Geometry of artificial bird impactor (in mm) and (b) high-speed video images of bird strike test (by DLR).

A differentiation for tensile and compressive preloading was made here as limit loads and ultimate loads are often given as strain values (microstrains) for the tensile load case and as a relation to the buckling load for the compressive load case.

The bird projectile was shot against the plate centre with the soft body impactor material flowing and spreading across the target surface (Figure 3(b)).

Posttest damage assessment in the first instance was performed with nondestructive damage inspection methods like ultrasonic C-scanning and microcomputer tomography. However, as the damage inside the plates even for the highest impact velocity was rather small and the exact type of damage was difficult to determine, micrographs were taken in order to get a detailed look into the damaged laminate.

For the lowest velocity of $90-100 \mathrm{~m} / \mathrm{s}$ (approx. 140 J) there was almost no damage in none of the test plates, which shows that the deformation of the impacted plate remains in the elastic domain and the biggest part of the initial kinetic energy remains as residual kinetic energy of the spreading impactor material. For higher impact velocities the amount of internal damage increases, which is shown in Figure 4 for the specimens with tensile preload. The only damage mode occurring in this case is matrix cracking in the upper and lower plies due to tensile and compressive loads during plate bending and impactor contact forces, which was verified in the micrographs (Figure 5(a)). No delamination occurred in the plates with tensile preload for the given range of impact velocities.

It is worth noting that the type of damage changes for the three preload cases. In general, the amount of matrix cracking appeared to be higher for the tensile preloaded specimens. The specimen with compressive preload showed more localised internal matrix cracks and fibre blowout on the back surface (Figure 5(b)). This might be due to a softening effect of the compressive preload, which allows for higher bending deformations, in contrast to a stiffening effect of the tensile preload. This corresponds to results that were also reported in other studies [3,25]. The plate bending deformation was unfortunately not measured during the high-velocity impact tests and can only be assessed in the numerical simulation model.

\section{Model Development}

In aerospace engineering there is a strong interest in predictive numerical methods for damage assessment in vulnerability analyses of composite structures under foreign object impact [29]. In this context, a numerical approach was developed and investigated in this study to predict the impact damage of preloaded composite plates under bird strike loading. This is a very complex task in terms of accurate composite material modelling with intra- and interlaminar damage, hydrodynamic soft body impactor modelling, and fluid-structure interaction as well as implicitexplicit coupling for efficient preload modelling.

3.1. Composite Material Modelling. Different damage mechanisms occur in composite plates under impact loading that absorb part of the initial kinetic energy of the impactor and reduce the residual strength. Although they strongly depend on factors like plate thickness, boundary conditions, impact velocity, impactor mass, and geometry, they can often be identified as matrix cracking, delaminations, and finally fibre rupture. It is desired that all these potential failure modes are covered by the numerical model enabling their occurrence in the simulation as well. 


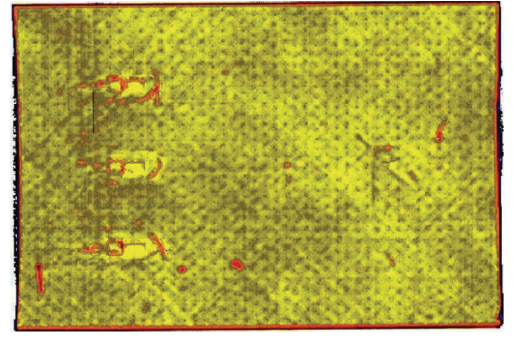

(a) $97 \mathrm{~m} / \mathrm{s}, 142 \mathrm{~J}$

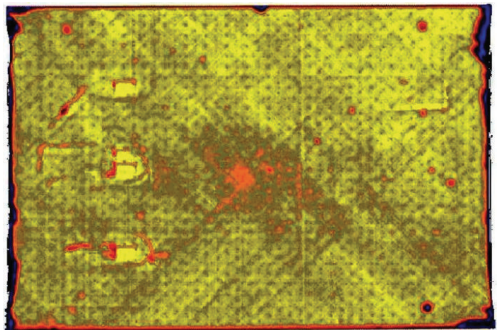

(b) $142 \mathrm{~m} / \mathrm{s}, 311 \mathrm{~J}$

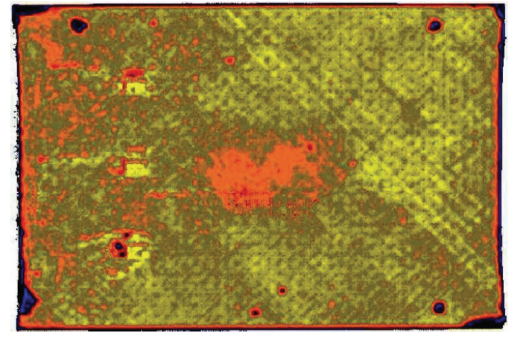

(c) $171 \mathrm{~m} / \mathrm{s}, 443 \mathrm{~J}$

FIGURE 4: Increasing damage with increasing impact velocity visualised by ultrasonic C-scans of specimens with tensile preload (no delaminations but only matrix cracking).

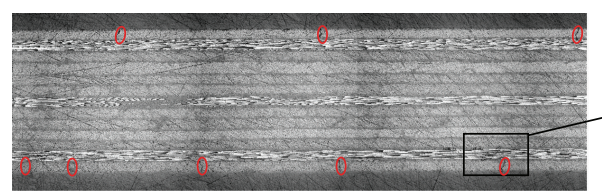

(a)
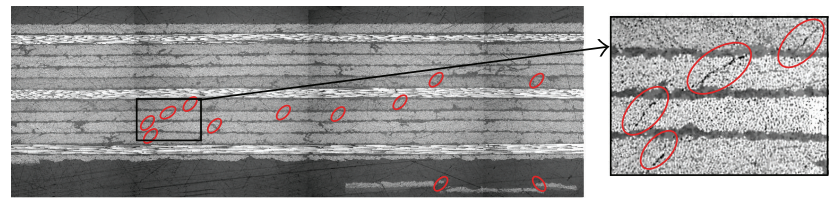

(b)

FIGURE 5: Posttest micrographs of specimen centre (a) with tensile preload and impact velocity of $171 \mathrm{~m} / \mathrm{s}$ (443 J) and (b) with compressive preload and impact velocity of $170 \mathrm{~m} / \mathrm{s}$ (449 J), matrix cracks are highlighted.

State of the art of intralaminar stiffness and failure modelling of the individual ply is either the assumption of linear elastic stiffness behaviour in combination with failure criteria or the utilisation of continuum-damage-mechanics-(CDM-) based models with a continuous stiffness degradation under increasing load. In the current study, the standard composite material model in the commercial FE code Abaqus was used, which is based on an orthotropic linear elastic formulation and Hashin failure criteria for damage initiation:

(i) tensile failure in fibre direction $\left(\widehat{\sigma}_{11} \geq 0\right)$ :

$$
F_{f}^{t}=\left(\frac{\hat{\sigma}_{11}}{X_{t}}\right)^{2}+\alpha\left(\frac{\hat{\tau}_{12}}{S_{L}}\right)^{2}, \quad \geq 1 \text { failure, }<1 \text { elastic, }
$$

(ii) compressive failure in fibre direction $\left(\widehat{\sigma}_{11} \leq 0\right)$ :

$$
F_{f}^{c}=\left(\frac{\widehat{\sigma}_{11}}{X_{c}}\right)^{2}, \quad \geq 1 \text { failure, }<1 \text { elastic, }
$$

(iii) tensile failure in matrix direction $\left(\widehat{\sigma}_{22} \geq 0\right)$ :

$$
F_{m}^{t}=\left(\frac{\hat{\sigma}_{22}}{Y_{t}}\right)^{2}+\left(\frac{\hat{\tau}_{12}}{S_{L}}\right)^{2}, \quad \geq 1 \text { failure, }<1 \text { elastic, }
$$

(iv) compressive failure in matrix direction $\left(\hat{\sigma}_{22} \leq 0\right)$ :

$$
\begin{aligned}
F_{m}^{c}=\left(\frac{\hat{\sigma}_{22}}{2 S_{T}}\right)^{2}+\left[\left(\frac{Y_{c}}{2 S_{T}}\right)^{2}-1\right] \frac{\hat{\sigma}_{22}}{Y_{c}}+\left(\frac{\hat{\tau}_{12}}{S_{L}}\right)^{2} \\
\geq 1 \text { failure, }<1 \text { elastic, }
\end{aligned}
$$

with $\widehat{\sigma}_{11}, \hat{\sigma}_{22}$, and $\hat{\tau}_{12}$ as the components of the effective stress tensor, $X_{t}$ and $X_{c}$ as the tensile and compressive strength values in fibre direction, $Y_{t}$ and $Y_{c}$ as the tensile and compressive strength values in matrix direction, $S_{L}$ and $S_{T}$ as the shear strength values in longitudinal and transversal direction, and $\alpha$ as the shear stress interaction coefficient.

Damage evolution until complete erosion of the ply is controlled by fracture energies in fibre and matrix direction for compression and tension with a linear stiffness degradation. All material parameters used for this model were taken from the coupon test results mentioned before or from data sheets of the manufacturer.

8-node continuum shell elements of type SC8R with reduced integration and enhanced hourglass formulation were used for the composite material modelling. An element size of $2.5 \mathrm{~mm}$ was chosen as the a result of a convergence study in terms of results accuracy and computational efficiency.

3.2. Delamination Modelling. The separation of adjacent plies due to normal or shear loads, referred to as delamination, absorbs impact energy and decreases the laminate stiffness and therefore needs to be covered by the model as well. Because delaminations cannot be represented inside the continuum shell elements, the laminate was divided into a certain number of sublaminates with cohesive interfaces in between, which can fail during the simulation according to a specified failure law. This approach is referred to as "stacked shell" approach and consists of continuum shell elements with cohesive elements in between. The utilisation of a cohesive contact formulation as an alternative was also investigated but could finally not be adopted due to lack of stability. The cohesive elements of type COH3D8R were modelled with zero initial thickness so that the total laminate thickness is not influenced by the additional element layers. The number of these cohesive interfaces inside the 13-ply 


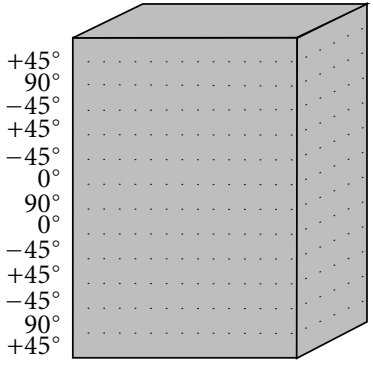

(a) No cohesive interfaces

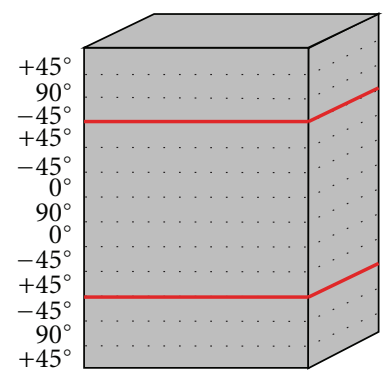

(b) 2 cohesive interfaces

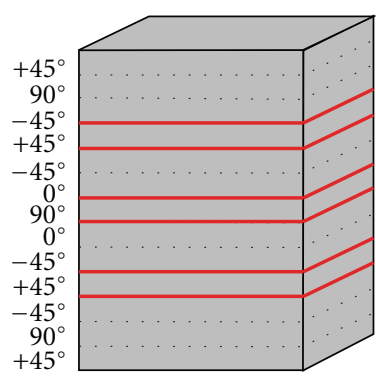

(c) 6 cohesive interfaces

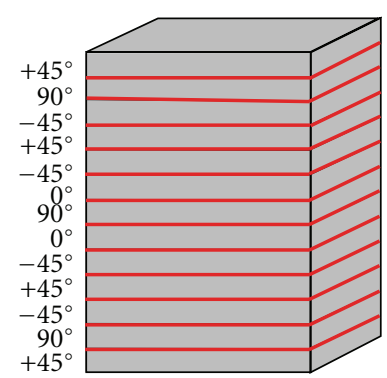

(d) 12 cohesive interfaces

FIGURE 6: Illustration of investigated delamination modelling approaches.

laminate was a parameter of investigation and the following options were analysed:

(i) no cohesive interfaces (no delamination, Figure 6(a));

(ii) 2 cohesive interfaces as an efficient, simplified "macrorepresentation" of delaminations that was also used in [17] (Figure 6(b));

(iii) 6 cohesive interfaces, between all plies with a difference of orientation of $90^{\circ}$ (Figure 6(c)) as they are prone to delaminations due to large differences in stiffness;

(iv) 12 cohesive interfaces, between all plies, most realistic and expensive modelling approach (Figure 6(d)).

On the one hand, a higher number of delamination interfaces are desired as the model becomes more realistic, but, on the other hand, the computational cost increases significantly due to the higher number of model degrees of freedom due to more cohesive and shell elements and the reduced explicit time step due to shorter element lengths. A simplification is typically necessary today to obtain industry-relevant calculation times. The accurate representation of the correct bending stiffness of all four approaches was assessed in a preliminary cantilever beam study and proved consistency within $5 \%$ of the analytical reference solution.

The failure law of the cohesive elements is based on the classical cohesive zone model (CZM) [30] with a bilinear traction-separation approach, characterised by the critical energy release rates for mode I $\left(G_{\text {IC }}\right)$ and mode II $\left(G_{\text {IIC }}\right)$ as the area under the bilinear curves. These critical energy release rates for T800S/M21 material were taken from Ilyas et al. [31] as $G_{\mathrm{IC}}=765 \mathrm{~J} / \mathrm{m}^{2}$ and $G_{\text {IIC }}=1250 \mathrm{~J} / \mathrm{m}^{2}$. Besides these measurable parameters, further penalty parameters need to be defined in the model, like the maximum interface stresses $t_{i}^{0}$ and the stiffness values $K_{\mathrm{xx}}$ for the elastic interface behaviour. They were determined using the approach proposed by Diehl [32] and validated by performing double cantilever beam (DCB) test simulations for mode I and endnotched flexure (ENF) test simulations for mode II and comparing the results with available coupon tests (Figure 7) $[33,34]$. Following a mesh convergence study, a final mesh size of $1.0 \mathrm{~mm}$ for the cohesive elements was selected, which were attached to the continuum shell elements of the sublaminates by tie constraints.

3.3. Soft Body Impactor Modelling. The projectile used in the current study was made of gelatine, which is a standard material in aerospace engineering for artificial birds used in precertification bird strike tests in order to improve convenience, cost, and reproducibility compared to tests with real birds, which can exhibit large scatter due to their irregular shape. When a bird hits the surface of an aeronautical structure at the velocity of interest, it behaves like a fluid and flows along the surface with a relatively large contact area. Such a pressure loading was found to be well represented by using water-based gelatine projectiles and simplified geometries like cylinders with hemispherical ends [35].

Since real birds and artificial gelatine birds are mostly composed of water, a water-like hydrodynamic response can be considered as a valid approximation for a constitutive model for bird strike analyses. An equation of state (EOS) is typically used for the hydrodynamic modelling, which describes the pressure-volume relationship with parameters of water at room temperature. The high deformations of the spreading material are a major challenge for computational simulations of soft body impacts. Two different soft body impactor modelling methods were investigated and compared in the framework of this study: the Lagrangian and the Eulerian approach.

The Lagrangian modelling method is the standard approach for most structural finite element analyses with the nodes of the Lagrangian mesh being associated with the material and therefore following the material under motion and deformation. The major problem of the Lagrangian bird impactor models is the severe mesh deformation. Large distortions of the elements may lead to inaccurate results, severe hourglassing, reduced time steps, and even error termination, which has to be prevented with adequate element erosion criteria [36]. The Lagrangian bird impactor model in this study was meshed with $3 \mathrm{~mm} \mathrm{C3D} 8 \mathrm{R}$ solid elements leading to 1600 elements in total. A tabular EOS with parameters given in [37] was used with element erosion being controlled by a damage initiation criterion at $400 \%$ element strain. 


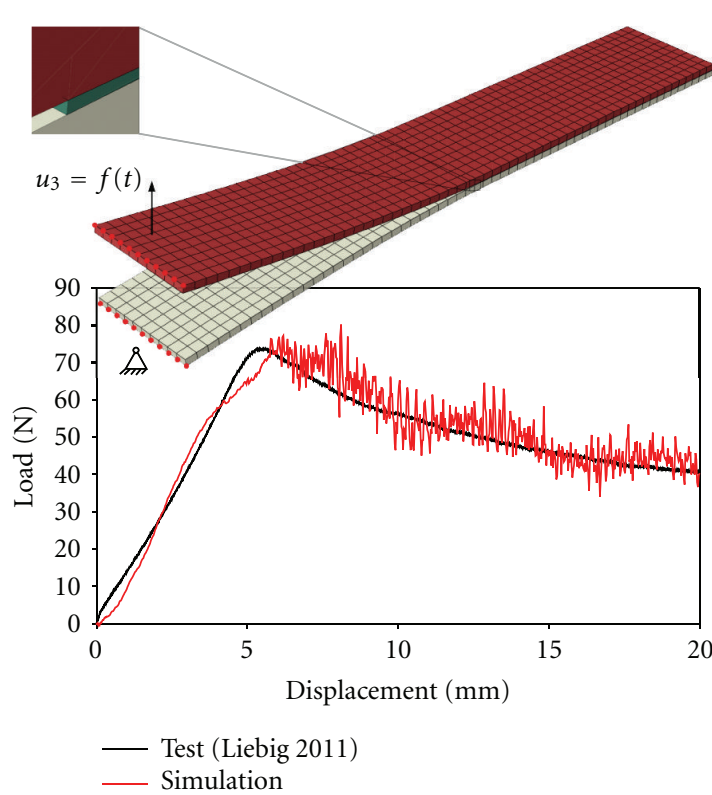

(a)

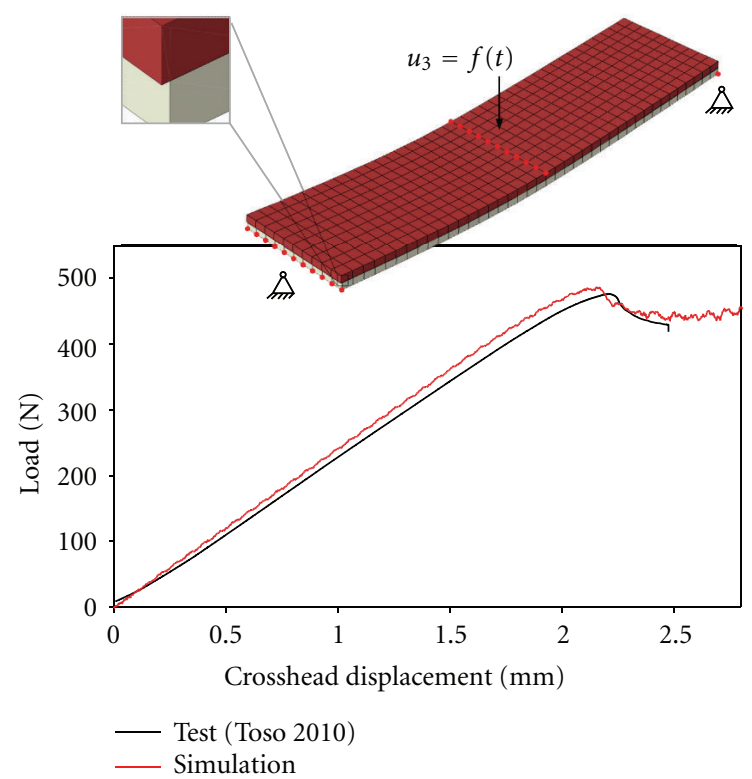

(b)

FIGURE 7: Validation of delamination model in simulations of (a) DCB and (b) ENF tests of T800S/M21 specimens.

A promising alternative to the Lagrangian impactor is the Eulerian modelling technique, where the mesh remains fixed in space and the material flows through the mesh. Because the mesh does not move, mesh deformations do not occur and the explicit time step is not influenced. Stability problems due to excessive element deformation do not occur as well. Since in a bird strike simulation typically only the impactor is modelled as a fluid-like body with the Eulerian elements and the target as a solid structure with the Lagrangian elements, a coupled Eulerian-Lagrangian (CEL) approach is used for this fluid-structure interaction problem. Because the mesh in the classical Eulerian technique is fixed in space, the computational domain should cover not only the region where the material currently exists but also additional void space to represent the region where material may exist at a later time of interest. Thus, the computational domain for structural analyses with the classical Eulerian technique is relatively large, leading to high computational cost due to the high number of elements and the costintensive calculation of element volume fractions and interactions. Typically, the element size of the Eulerian mesh has to be defined very small in order to achieve accurate results. In this study, a mesh size of $3 \mathrm{~mm}$ was selected for the impact zone and a coarser mesh of $15 \mathrm{~mm}$ in a larger distance. The Eulerian elements of the type EC3D8R were used combined with a Mie-Grüneisen EOS ( $u_{s}-u_{p}$ approach) adopted from [38]. In contrast to the Lagrangian bird model, no element erosion criterion is necessary here.

In order to validate the bird impactor models, a common approach is to use experimental bird strike test data from impacts either on instrumented rigid surfaces to compare the pressure-time history with the numerical results (Figure 8) or on flexible metallic plates to compare the residual plastic deformation after impact (Figure 9). Aircraft manufacturers typically use internal test data, but a large set of publicly accessible experimental bird impact test data can also be found in the literature [39-41]. For both load cases, both the Lagrangian and Eulerian bird models led to promising results. However, the initial contact force peak in the impact simulation on a rigid surface seems to be overpredicted for both models (Figure 8 ). The experimentally measured plastic deformation of the $6.35 \mathrm{~mm}$ thick flexible aluminium plate of $42.86 \mathrm{~mm}$ [40] was predicted by the Lagrangian model with a value of $47.58 \mathrm{~mm}$ and by the Eulerian model with a value of $45.22 \mathrm{~mm}$, which is an overprediction of $11 \%$ and $5.5 \%$ (Figure 9). The accuracy of the Eulerian model was slightly better in both validation studies. However, the Eulerian impact simulations took 9-10 times longer to complete. All in all, these results gave good confidence to use the bird impactor models for the following bird strike simulations on composite plates.

3.4. Preload Modelling. In the numerical simulation, there are different possibilities to how to model the preloading before impact. In most studies in the literature the preloading was also performed within the explicit calculation step [9, 17]. If oscillations can be avoided, this approach is working well, but it is relatively expensive. Typically half of the computational cost is ascribed to the preloading, half to the impact simulation. A much more elegant approach, which is straight-forward in Abaqus and was applied in this study, is implicit-explicit coupling. The preloading is performed during an implicit calculation step in Abaqus/Standard, which takes only a few minutes, and then the model and stress state are transferred to a calculation with Abaqus/Explicit for the impact loading. 


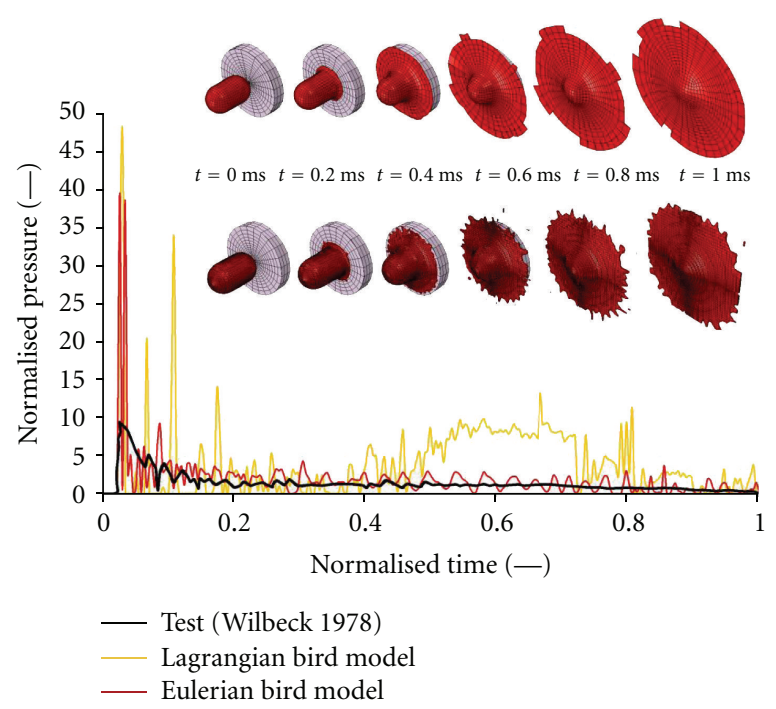

FIGURE 8: Validation of bird impactor models, impact on rigid plate: pressure-time-plots.
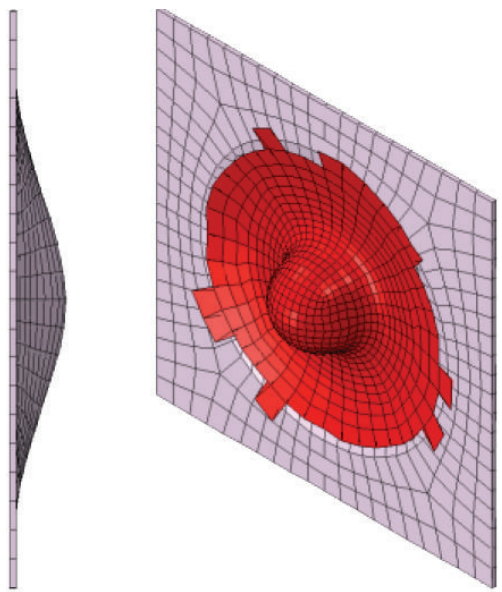

(a) Lagrangian
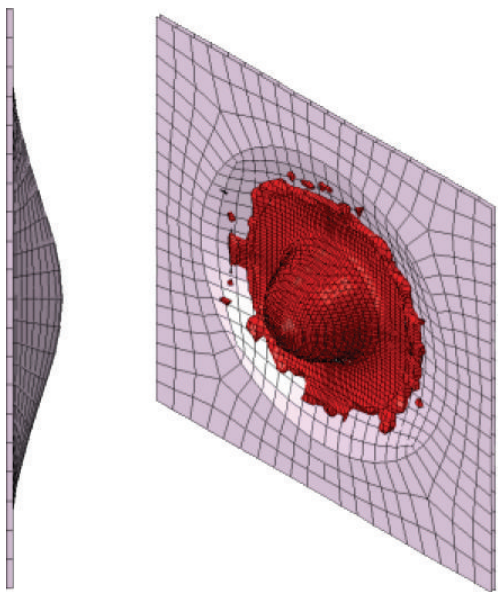

(b) Eulerian

Figure 9: Validation of bird impactor models, impact on flexible metallic plate: plate deformation.

\section{Simulation Results}

After successful separate validation of all model components, that is, composite and delamination model as well as bird impactor model, everything was combined in bird strike simulation models on preloaded composite plates. A large number of bird strike simulations was performed in order to represent the whole test matrix and to analyse the influence of different parameters, that is,

(i) preload: compression, unloaded, and tension;

(ii) impact velocity: $100 \mathrm{~m} / \mathrm{s}, 140 \mathrm{~m} / \mathrm{s}$, and $170 \mathrm{~m} / \mathrm{s}$;

(iii) impactor model: Lagrangian and Eulerian;

(iv) delamination interfaces: none, 2, 6, and 12 .

Figure 10 gives an impression of the numerical bird spreading behaviour of the Lagrangian and Eulerian impactor models, which appears to be similar to the high-speed test video. The calculation time for the Eulerian model was about 2.5 times higher than that of the Lagrangian model. Specific output values have been used for the damage analysis in the simulation model. Interlaminar damage was visualised using the variable SDEG, which illustrates the stiffness degradation of the cohesive elements. Of course, complete delamination appears by eroded cohesive elements, but the variable SDEG highlights cohesive elements that are already damaged by not completely failed yet. Intralaminar damage can best be visualised by plotting the variable DAMAGEMT, which corresponds to matrix tensile failure. This failure mode is typically the first and in this study also the only failure mode occurring in the model, similar to the matrix cracking observed in the posttest micrographs. An example of postimpact damage status is shown in Figure 11 for a sample with tensile preload and an impact velocity of $100 \mathrm{~m} / \mathrm{s}$, modelled with two delamination interfaces.

It can be noted that the extent of damage is slightly higher than in the experimental test sample, especially for the Eulerian impactor. The physical sample showed no damage and a pure elastic response, but in the simulation model there are already matrix cracks and even delaminations visible. This overprediction of damage was observed in all simulations.

As a first measure, the influence of different numbers of cohesive interfaces was investigated. Indeed, the increase from two to six or even twelve delamination interfaces improved the results in a sense that the extent of interlaminar damage was smaller in the individual interface and the global response was much more realistic. This improvement of results quality, however, had to be paid by a significant increase in computational cost and frequent model instabilities due to very complex contact calculations.

The damage overprediction was finally attributed to the high initial peak contact force of the bird impact loading, which was already pointed out in the bird validation study and which was also reported in several other papers [42-45]. Therefore, the model validation by just comparing the plastic deformation of a flexible metallic plate might not be sufficient as this peak load has no crucial effect here. However, during the impact simulation on a laminated 


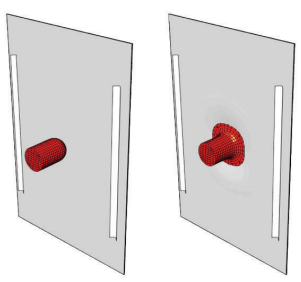

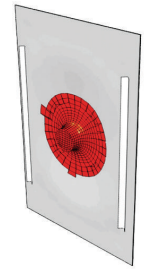

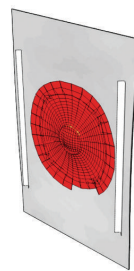

(a)
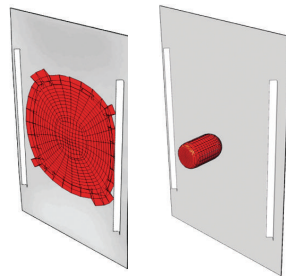

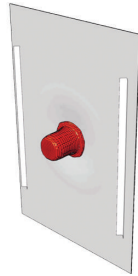

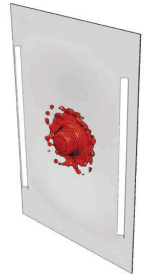
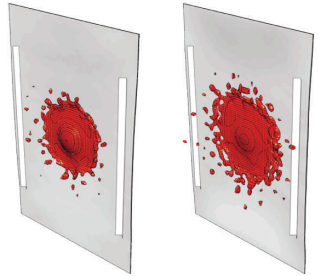

(b)

FIGURE 10: Bird strike simulation on composite plate with the (a) Lagrangian and (b) Eulerian impactor models.

composite plate, significant intralaminar and delamination damage is already initiated in the moment of contact, which grows during the remaining pressure loading phase, leading to an overprediction of damage. One measure to obtain more realistic results can be the improvement of the EOS of the bird impactor model. Ivancevic and Smojver [44], for example, modified the EOS as a user-defined material law to account for $10 \%$ porosity and obtained much lower peak pressure forces compared to a standard Mie-Grüneisen EOS formulation without porosity used before [46], although still overpredicting the test data from reference [39]. Furthermore, the contact algorithm, typically a penalty contact formulation, and its contact stiffness adjustment appear to be one of the key factors on the way to realistic bird strike simulations on composite plates.

Finally, the influence of prestress on the impact response was assessed in the simulation. The tensile preloading led to less bending deformation of the plate compared to the unloaded case (Figure 12). Consequently, the interlaminar damage is slightly smaller. The intralaminar damage was found to be a little higher, which corresponds to the experimental observations.

In case of compressive preload, plate buckling becomes an issue due to the small thickness of the composite plates. Different buckling modes occurred depending on the level of compressive prestrain, which can lead to an initial deflection of the plate centre towards or away from the impactor before impact. In this study, the deflection was always selected to be away from the impactor. The assessment of the impact simulation results showed that the global deflection of the preloaded plate is higher than that of the unloaded plate (Figure 12), which is explained both by the initial buckling deformation and by the compressive preloading. This higher bending deformation leads to slightly higher interlaminar damage, which was visible for all impact velocities. The compressive preload was found to initiate more delamination and more localized failure upon impact. The experimental results in terms of ultrasonic C-scans and micrographs support these pretest simulation results, highlighting the benefit of such numerical tools.

\section{Conclusions}

An experimental and numerical study of the high-velocity impact of a soft body projectile on preloaded composite plates was performed. This complex simulation task in terms of nonlinear composite damage modelling with inter- and intralaminar failure modes, implicit-explicit coupling for efficient preload modelling, and fluid-structure interaction calculation with hydrodynamic bird impactor models showed that current commercial software tools are efficient and robust for the prediction of foreign object impact damage, but the process of accurate model validation is complex and further improvements to increase simulation accuracy are necessary. follows.

The major conclusions of this study are summarised as

(i) The water-like soft body projectile flows along the surface leading to a distributed, nonlocal contact area, resulting in a mostly elastic response of the relatively thin plate and only few matrix cracks for the complete range of velocities (up to $171 \mathrm{~m} / \mathrm{s}$ ) and impact energies (up to $443 \mathrm{~J}$ ).

(ii) Tensile preload leads to less bending deformation of the target plate and consequently less interlaminar but more intralaminar matrix cracking damage, which primarily appeared in the two outer layers.

(iii) Compressive preload allows for higher plate bending deformation and therefore more interlaminar damage. The intralaminar damage in terms of matrix cracking appeared to be more localised in the plate centre and distributed through several internal layers.

(iv) Both the Lagrangian and Eulerian impactor models lead to promising results, as long as an appropriate strain-based element erosion criterion was used for the Lagrangian model. The Eulerian model was significantly more expensive and led to slightly more damage in the composite plates.

(v) In correlation to numerous other research papers, both the Lagrangian and Eulerian impactor models overpredicted the initial contact pressure, leading to increased inter- and intralaminar damage in the composite target structure when used with a classical Mie-Grüneisen or tabular equation of state for water at room temperature. Improvements to obtain lower peak pressures beyond the increase of porosity are mandatory.

(vi) The contact algorithm is a major part of the bird strike simulation, and it is desirable that the software allows the user to influence the penalty stiffness calculation to avoid overstiff contact reaction forces. 


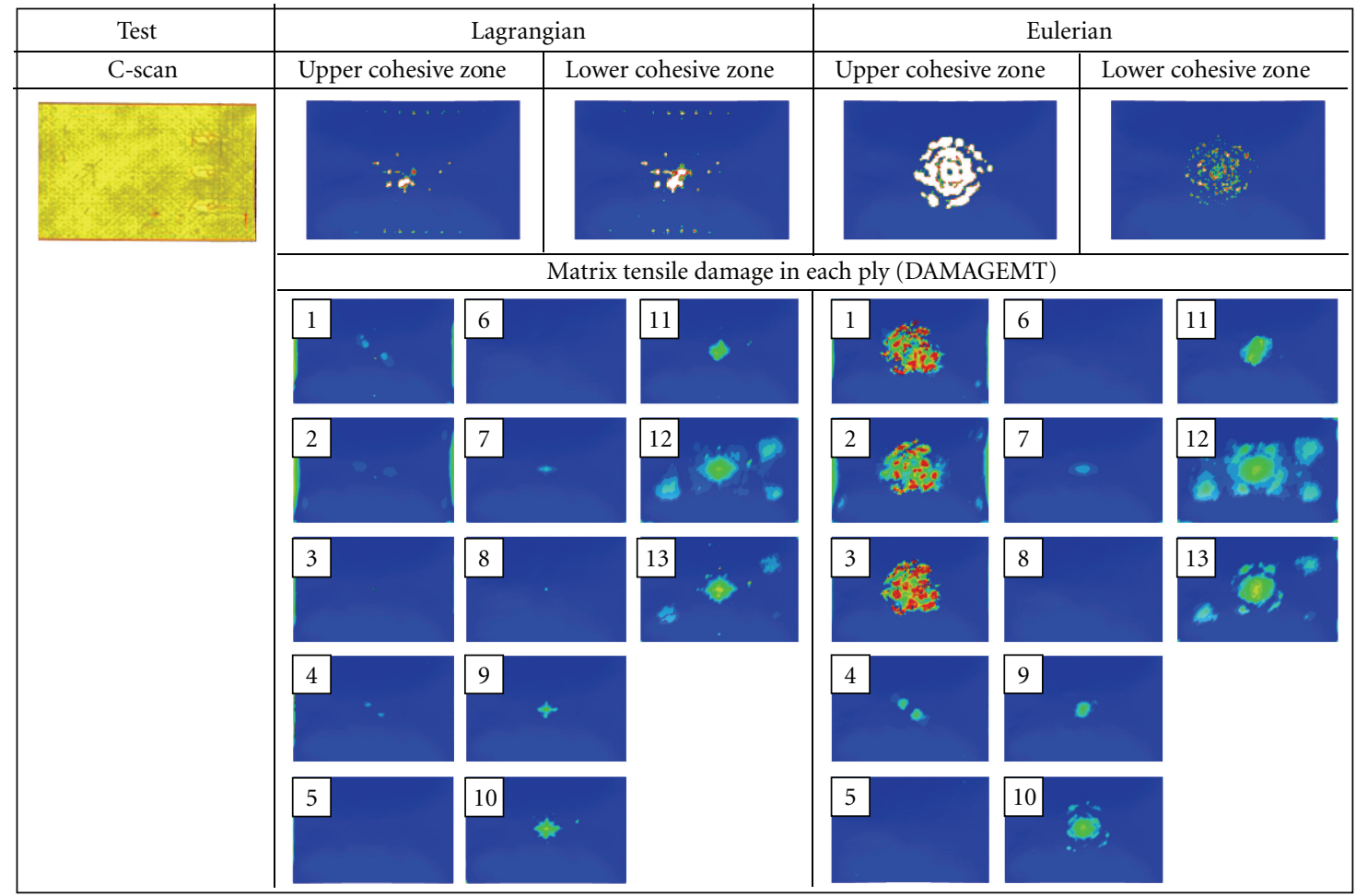

FIGURE 11: Interlaminar and intralaminar damage after bird impact with $100 \mathrm{~m} / \mathrm{s}$.

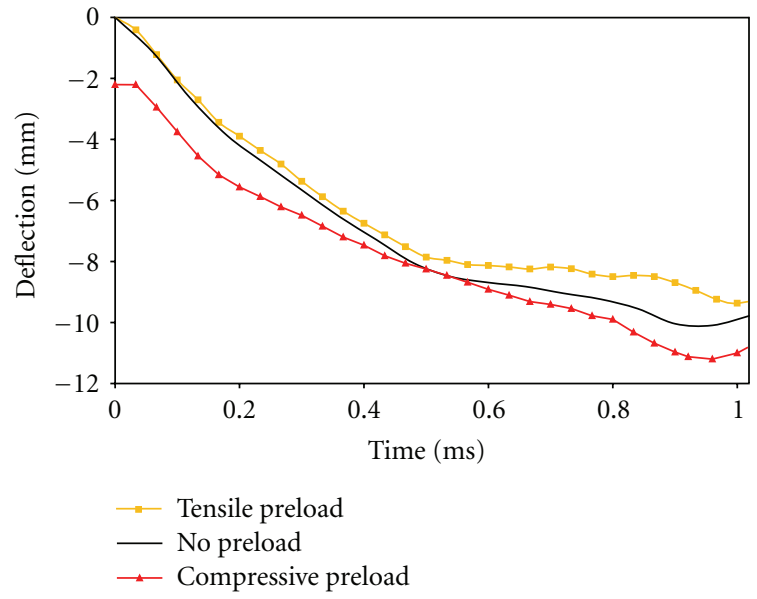

Figure 12: Predicted deflection of plate centre versus time under bird impact with $100 \mathrm{~m} / \mathrm{s}$.

(vii) The more the delamination interfaces are used, the more realistic the results appeared. The extent of delaminations with only two interfaces was much overpredicted. However, a model with delamination interface between each ply was very expensive and showed a lack of stability.

\section{Acknowledgments}

This study has been funded by the European Commission FP7/2007-2013 under grant agreement no.
213371 within the European project MAAXIMUS (http://www.maaximus.eu/). The authors would like to thank Nathalie Toso, Dominik Schueler, and Albert Reiter from DLR Stuttgart for performing the bird strike tests and Sindy Engel for manufacturing the composite plates that were used in this study.

\section{References}

[1] S. T. Chiu, Y. Y. Liou, Y. C. Chang, and C. L. Ong, "Low velocity impact behavior of prestressed composite laminates," Materials Chemistry and Physics, vol. 47, no. 2, pp. 268-272, 1997.

[2] M. D. Robb, W. S. Arnold, and I. H. Marshall, "The damage tolerance of GRP laminates under biaxial prestress," Composite Structures, vol. 32, no. 1-4, pp. 141-149, 1995.

[3] A. Kursun and M. Senel, "Investigation of the effect of low-velocity impact on composite plates with preloading," Experimental Techniques. In press.

[4] J. H. Tweed, R. J. Lee, R. J. Dyson, N. L. Hancox, and J. C. McCarthy, "Impact performance of stressed composites," in Proceedings of the 7th European Conference on Composite Materials (ECCM '96), pp. 111-116, London, UK, May 1996.

[5] B. R. Butcher, "The impact resistance of unidirectional CFRP under tensile stress," Fibre Science and Technology, vol. 12, no. 4, pp. 295-326, 1979.

[6] B. R. Butcher and P. J. Fernback, "Impact resistance of unidirectional CFRP under tensile stress: further experimental variables," Fibre Science and Technology, vol. 14, no. 1, pp. 41$58,1981$. 
[7] K. M. Mikkor, R. S. Thomson, I. Herszberg, T. Weller, and A. P. Mouritz, "Finite element modelling of impact on preloaded composite panels," Composite Structures, vol. 75, no. 1-4, pp. 501-513, 2006.

[8] B. Whittingham, I. H. Marshall, T. Mitrevski, and R. Jones, "The response of composite structures with pre-stress subject to low velocity impact damage," Composite Structures, vol. 66, no. 1-4, pp. 685-698, 2004.

[9] A. K. Pickett, M. R. C. Fouinneteau, and P. Middendorf, "Test and modelling of impact on pre-loaded composite panels," Applied Composite Materials, vol. 16, no. 4, pp. 225-244, 2009.

[10] A. D. Kelkar, J. Sankar, K. Rajeev, R. J. Aschenbrenner, and G. Schoeppner, "Analysis of tensile preloaded composites subjected to low-velocity impact loads," in Proceedings of the 39th AIAA/ASME/ASCE/AHS/ASC Structures, Structural Dynamics, and Materials Conference, pp. 1978-1987, Long Beach, Calif, USA, April 1998.

[11] A. D. Kelkar, J. Sankar, and C. Grace, "Behavior of tensile preloaded composites subjected to low-velocity impact loads," American Society of Mechanical Engineers, vol. 369, pp. 39-46, 1997.

[12] T. Mitrevski, I. H. Marshall, R. S. Thomson, and R. Jones, "Low-velocity impacts on preloaded GFRP specimens with various impactor shapes," Composite Structures, vol. 76, no. 3, pp. 209-217, 2006.

[13] A. Nettles, V. Daniel, and C. Branscomb, "The effects of tensile preloads on the impact response of carbon/epoxy laminates," in Proceedings of the 40th International SAMPE Symposium, pp. 1019-1025, Anaheim, Calif, USA, May 1995.

[14] D. C. Phillips, N. Park, and R. J. Lee, "The impact behaviour of high performance, ceramic matrix fibre composites," Composites Science and Technology, vol. 37, no. 1-3, pp. 249265, 1990.

[15] N. Park, "The impact response of composites under stress," in Proceedings of the 4th International Conference, Fibre Reinforced Composites (FRC '90), pp. 137-143, Institution of Mechanical Engineers, March 1990.

[16] B. V. Sankar and C. T. Sun, "Low-velocity impact damage in graphite-epoxy laminates subjected to tensile initial stresses," AIAA journal, vol. 24, no. 3, pp. 470-471, 1986.

[17] S. Heimbs, S. Heller, P. Middendorf, F. Hähnel, and J. Weiße, "Low velocity impact on CFRP plates with compressive preload: test and modelling," International Journal of Impact Engineering, vol. 36, no. 10-11, pp. 1182-1193, 2009.

[18] X. Zhang, G. A. O. Davies, and D. Hitchings, "Impact damage with compressive preload and post-impact compression of carbon composite plates," International Journal of Impact Engineering, vol. 22, no. 5, pp. 485-509, 1999.

[19] H. Morlo and J. Kunz, "Impact behaviour of loaded composites," in Proceedings of the 4th European Conference on Composite Materials, Stuttgart, Germany, September 1990.

[20] I. H. Choi, "Low-velocity impact analysis of composite laminates under initial in-plane load," Composite Structures, vol. 86, no. 1-3, pp. 251-257, 2008.

[21] C. T. Sun and J. K. Chen, "On the impact of initially stressed composite laminates," Journal of Composite Materials, vol. 19, no. 6, pp. 490-504, 1985.

[22] C. T. Sun and S. Chattopadhyay, "Dynamic response of anisotropic laminated plates under initial stress to impact of a mass," Journal of Applied Mechanics, Transactions ASME, vol. 42, no. 3, pp. 693-698, 1975.

[23] S. M. R. Khalili, R. K. Mittal, and N. M. Panah, "Analysis of fiber reinforced composite plates subjected to transverse impact in the presence of initial stresses," Composite Structures, vol. 77, no. 2, pp. 263-268, 2007.

[24] I. Herszberg, T. Weller, K. H. Leong, and M. K. Bannister, “The residual tensile strength of stitched and unstitched carbon/ epoxy laminates impacted under tensile load," in Proceedings of the 1st Australasian Congress on Applied Mechanics, pp. 309314, Melbourne, Australia, February 1996.

[25] D. Schueler, N. Toso-Pentecote, and H. Voggenreiter, "Modelling of high velocity impact on preloaded composite panels," in Proceedings of the 3rd ECCOMAS Thematic Conference on the Mechanical Response of Composites, pp. 587-594, Composites, Hannover, Germany, September 2011.

[26] U. K. Vaidya and B. Shafiq, "Dynamic response of navy relevant laminated and sandwich composites subjected to complex impact loads," in Workshop on Dynamic Failure of Composite and Sandwich Structures, pp. 39-44, Toulouse, France, June 2011.

[27] S. K. Garcia-Castillo, S. Sanchez-Saez, J. Lopez-Puente, E. Barbero, and C. Navarro, "Impact behaviour of preloaded glass/polyester woven plates," Composites Science and Technology, vol. 69, no. 6, pp. 711-717, 2009.

[28] S. K. Garcia-Castillo, S. Sanchez-Saez, E. Barbero, and C. Navarro, "Response of pre-loaded laminate composite plates subject to high velocity impact," Journal de Physique IV, vol. 134, no. 1, pp. 1257-1263, 2006.

[29] J. M. Guimard and S. Heimbs, "Towards the industrial assessment of bird strike simulations on composite laminate structures," in Proceedings of the 3rd ECCOMAS Thematic Conference on the Mechanical Response of Composites, Composites, Hannover, Germany, September 2011.

[30] R. Borg, L. Nilsson, and K. Simonsson, "Simulation of low velocity impact on fiber laminates using a cohesive zone based delamination model," Composites Science and Technology, vol. 64, no. 2, pp. 279-288, 2004.

[31] M. Ilyas, F. Lachaud, C. Espinosa, and M. Salaün, "Dynamic delamination of aeronautic structural composites by using cohesive finite elements," in Proceedings of the 17th International Conference on Composite Materials (ICCM '09), Edinburgh, UK, July 2009.

[32] T. Diehl, "On using a penalty-based cohesive-zone finite element approach, part I: elastic solution benchmarks," International Journal of Adhesion and Adhesives, vol. 28, no. 4-5, pp. 237-255, 2008.

[33] W. Liebig, "TUHH: MAAXIMUS achievements and way forward, status at M35," in Proceedings of the MAAXIMUS Technical Meeting, Technical University Hamburg-Harburg, Ottobrunn, Germany, February 15.

[34] N. Toso, D. Kohlgrüber, D. Schueler, M. Waimer, and A. Johnson, "MAAXIMUS WP 3.5-vulnerability, DLR test activities, DLR stuttgart," in Proceedings of the MAAXIMUS Technical Meeting, Hamburg, Germany, November 2010.

[35] J. S. Wilbeck and J. L. Rand, "Development of a substitute bird model," Journal of Engineering for Power, vol. 103, no. 4, pp. 725-730, 1981.

[36] S. Heimbs, "Computational methods for bird strike simulations: a review," Computers \& Structures, vol. 89, no. 23-24, pp. 2093-2112, 2011.

[37] Dassault Systems Simulia Corp, A Strategy for Bird Strike Simulations Using Abaqus/Explicit. Simulia Online Support Dokument, Answer-ID 4493 (Best Practices for Birdstrike Analysis), 2011.

[38] S. Heimbs, "Bird strike simulations on composite aircraft structures," in Proceedings of the SIMULIA Customer Conference (SCC '11), pp. 73-86, Barcelona, Spain, May 2011. 
[39] J. S. Wilbeck, "Impact behaviour of low strength projectiles," Report AFML-TR-77-134, US Air Force, 1978.

[40] C. J. Welsh and V. Centonze, "Aircraft transparency testingartificial birds," Report AEDC-TR-86-2, US Air Force, 1986.

[41] M. A. Lavoie, A. Gakwaya, M. N. Ensan, D. G. Zimcik, and D. Nandlall, "Bird's substitute tests results and evaluation of available numerical methods," International Journal of Impact Engineering, vol. 36, no. 10-11, pp. 1276-1287, 2009.

[42] S. Kari, J. Gabrys, and D. Lincks, "Birdstrike analysis of radome and wing leading edge using LS-DYNA," in Proceedings of the 5th International LS-DYNA Users Conference, Southfield, Mich, USA, September 1998.

[43] M. A. Lavoie, A. Gakwaya, M. N. Ensan, and D.G. Zimcik, "Validation of available approaches for numerical bird strike modelling tools," International Review of Mechanical Engineering, vol. 1, no. 4, pp. 380-389, 2007.

[44] D. Ivancevic and I. Smojver, "Hybrid approach in bird strike damage prediction on aeronautical composite structures," Composite Structures, vol. 94, no. 1, pp. 15-23, 2011.

[45] R. Hedayati and S. Ziaei-Rad, "Effect of impact orientation on bird strike analysis," International Journal of Vehicle Structures \& Systems, vol. 3, no. 3, pp. 184-191, 2011.

[46] I. Smojver and D. Ivancevic, "Numerical simulation of bird strike damage prediction in airplane flap structure," Composite Structures, vol. 92, no. 9, pp. 2016-2026, 2010. 

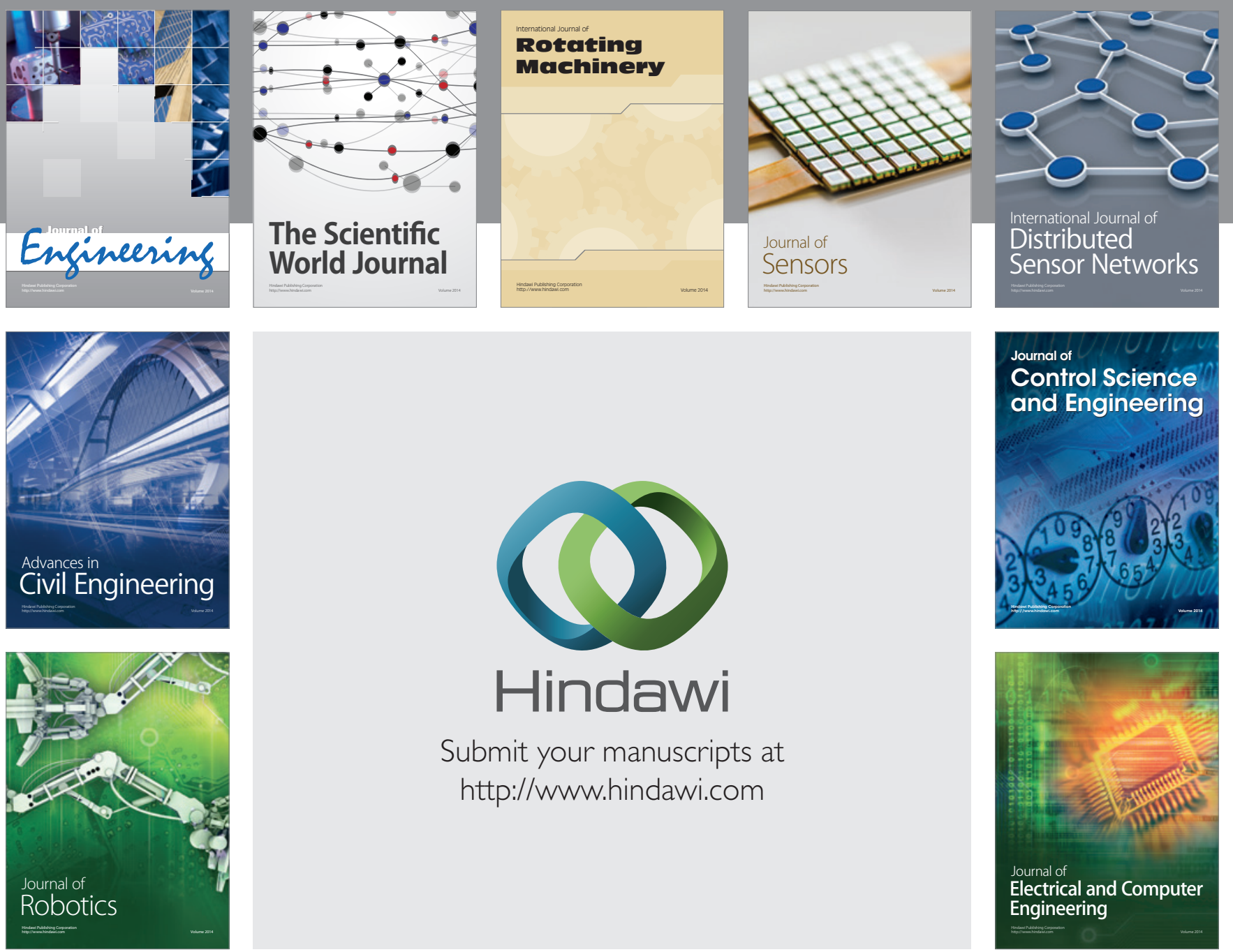

Submit your manuscripts at

http://www.hindawi.com
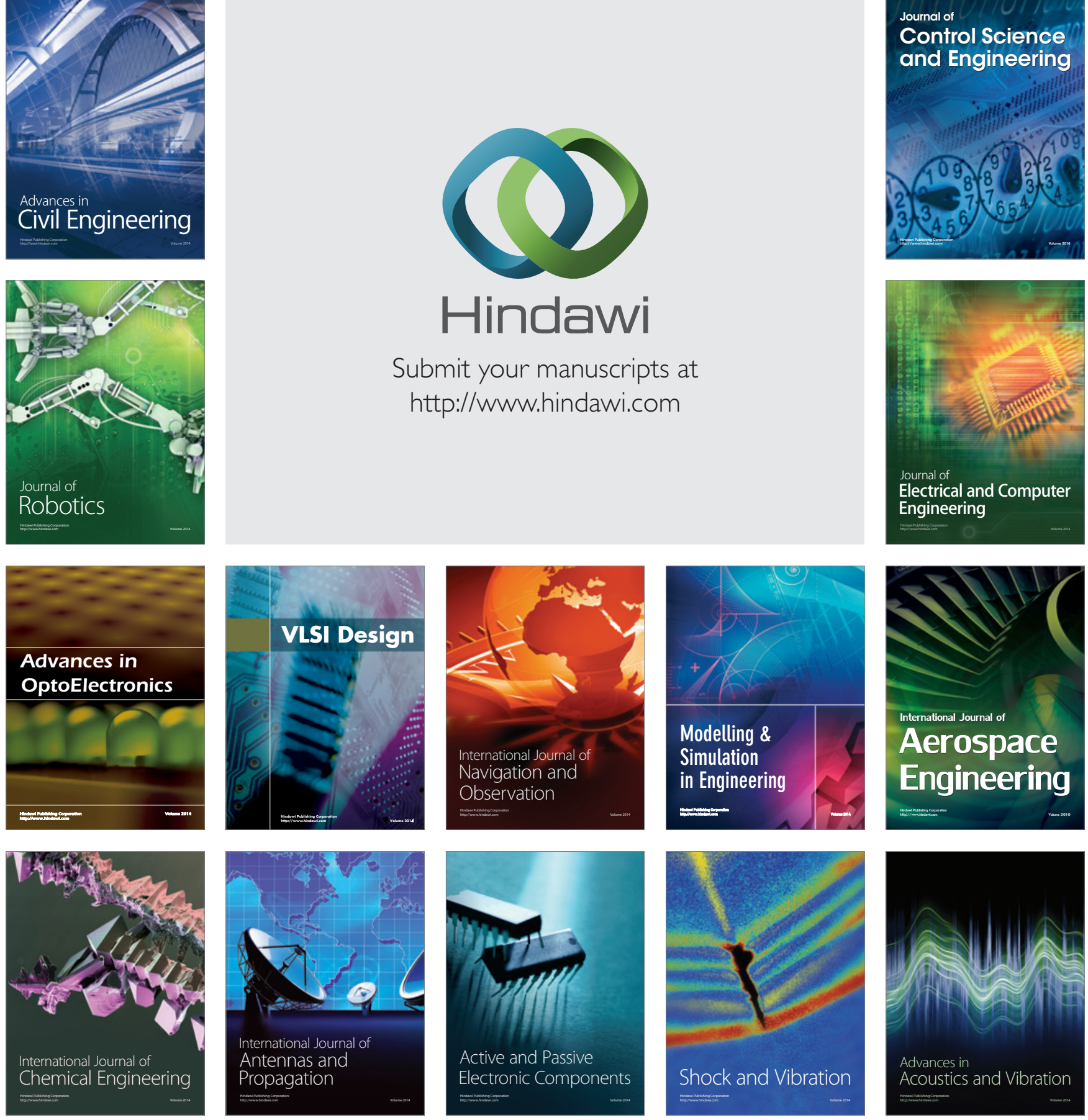